\title{
Bridging the gap: teaching university mathematics to high school students
}

$\begin{array}{lll}\text { P. J. Higgins } & & \text { D. F. Mullamphy } \\ & & \text { S. R. Belward } \\ & \end{array}$

(Received 5 February 2010; revised 23 August 2010)

\begin{abstract}
Over recent years there has been a lot of emphasis placed on the drop in standards of students entering first year university mathematics in Australia. The tertiary sector struggles to handle this increasing gap and, with pressure to maintain student numbers, a common response has been to reduce the difficulty level of the first year mathematics courses. This approach has had limited success, with students passing first year mathematics but lacking preparation for the higher years. If realistic change is to be made in bridging this gap, then the problem needs to be addressed at both the tertiary and secondary level. We investigate the successes and potential failures of running a tertiary level mathematics course over five years at four high schools in North Queensland. This has been a genuine team approach by both university academics and high school mathematics teachers and forged solid links between the sectors. The presence of academics in the high school classrooms as well as students and teachers attending university activities led to a greater understanding of perceived difficulties on
\end{abstract}

http://anziamj . austms.org.au/ojs/index.php/ANZIAMJ/article/view/2689 gives this article, (c) Austral. Mathematical Soc. 2010. Published September 3, 2010. ISSN 1446-8735. (Print two pages per sheet of paper.) Copies of this article must not be made otherwise available on the internet; instead link directly to this URL for this article. 
both sides. The 'Mathematics into high schools' program proves to be a small but significant start in helping to bridge the secondarytertiary gap.

\section{Contents}

1 Background

C641

2 The program

C643

3 Results

C645

4 Positive outcomes

C648

4.1 For the university . . . . . . . . . . . . . . . C648

4.2 For the school and students . . . . . . . . . . . . . C649

5 Potential problems

C649

6 Conclusion

C650

References

C652

\section{Background}

Over the last twenty years there has been a significant drop in the abilities of students entering first year mathematics at James Cook University (JCU) [3]. This problem is not unique to North Queensland and may be more significant at smaller universities where the intake of students are at a lower level. This is further emphasised in Queensland where the quality of mathematics amongst high school leavers appears to have fallen dramatically over the past decade. This perception is supported by a recent survey by Barry and Chapman 
held at the Australian Defence Force Academy (ADFA) which showed that students entering the academy from Queensland with similar entrance scores performed much worse than students from all other states [1]. Reasons for this decline may lie in the Queensland curriculum itself, but these reasons will not be discussed in this article. The problem of declining standards is worldwide and there are numerous articles to support this case in countries such as Canada [7], Ireland [6], Hong Kong [8] and Holland [5]. Heck and Van Gastel [5] stated that

In recent years, mathematics, economics, science and engineering departments at Dutch universities observed that the mathematical abilities of incoming students dropped significantly and that freshman had many problems in making the transition from school to university mathematics.

One of the responses by JCU to the drop in the abilities of incoming first year students was to redistribute the difficulty of the undergraduate mathematics subjects across the entire mathematics degree. This redistribution made the first three semesters of mathematics less demanding and moved all of the abstract, and more demanding material, into the final semester of second year. This tapering of the degree was amenable to our client departments but proved to be less satisfactory within the mathematics degree itself, where students were exposed to material that was much more difficult than what they had encountered in their earlier years. Overall, this approach proved unsatisfactory and, rather than decrease the difficulty level of the degree further, an alternative approach needed to be taken where both the tertiary and secondary sectors were involved.

In 2004, JCU teamed with a local high school teacher to bring tertiary mathematics into a local high school and form stronger links between the university and this school. The aims were to bring academics into the classroom to familiarise them with the teaching scene within the school system, as well as exposing students to university level material. This process was also aimed at familiarising students with university life and was to be 
extended to other schools over the following five years.

This program is not the first to bring university level subjects into the high schools. The teaching of first year university subjects at high school, on courses that give students credit if they subsequently enrol into university, is not new. At a presentation in 2006, MacKenzie [9] discussed the Headstart program taught out of USC and how it was introduced in an attempt to boost low tertiary uptake rates. However, although the structure of their program is similar to our own, the primary aims of the program differed significantly. In 2008, at the University of Nevada, Bellimo and Strapp [2] also identified the strong need for better preparing high school students for the rigours of first year mathematics. Their response was to suggest a new school subject which would be aimed specifically at strengthening the areas of mathematics needed for the study of tertiary mathematics. However, although these concepts sound promising, the program is yet to be implemented. Also in the Us, the Advanced Placement (AP) program brings "challenging, college-level courses into the high schools and enables students to demonstrate that they are ready for college-level work" [10]. Bressoud [4] notes that from 1990 until 2005 while the number of students taking the AP Calculus exam increased from 75,000 to 250,000, the fall enrollment in Calculus II actually decreased, from 110,000 to 106,000 .

\section{The program}

The program involved the teaching of a standard first year calculus course by a local school teacher. Initially the course was restricted to students doing both main stream high school calculus courses, but this condition was relaxed in later years. All materials were supplied by JCU in electronic form online, and students were given access to the JCU Blackboard site for the subject. As the university semester and high school terms do not correspond, high school students were given an additional four or five weeks in which to complete the course. However, great care was taken to treat the assessment of school 
students in the same manner as the mainstream class. The overall structure of the program was

- the entire course was taught at the school by the school teacher involved,

- the academics would travel to the school and assist in the weekly tutorials,

- the students would attend a formal lecture at the university,

- the students would sit the mid-semester test at the university,

- the students would sit the final exam under university conditions,

- the students were added to the class list and graded with the mainstream class.

In the first year of the course, one high school was involved with a single teacher and small class of six students. Over the next five years, the program would increase to include five schools in three towns. The heavy demand by schools to be included in the program could not be met by the limited number of academic and school staff involved and hence the program was capped at a maximum of five schools. A number of schools had also shown interest in the program with the belief that the teaching was to be done by the university. This was not the case and, if the program is to succeed, the school must have its own highly motivated and capable teacher.

Of the five high schools that have participated in the program, three are from the Catholic system and two are public state high schools. We did not observe any significant difference in the abilities of the students from different schools or types of schools. 


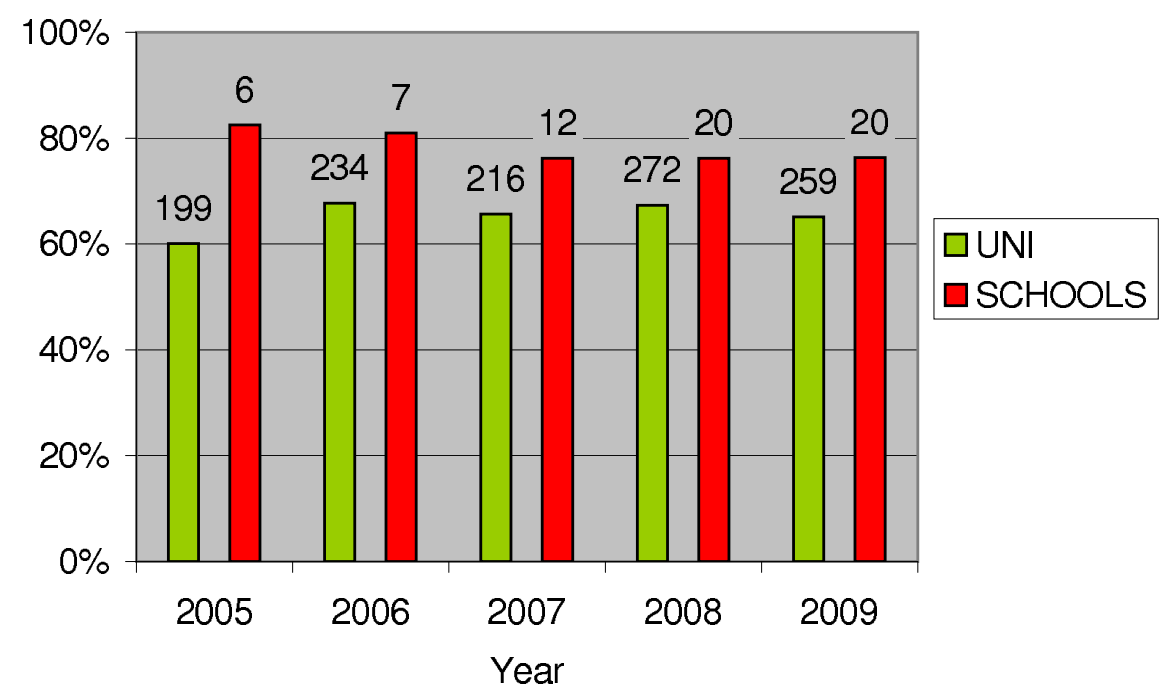

Figure 1: Comparing on-course assessment results for university and high school students for years 2005-2009. The number of students in each class is at the top of the bars.

\section{Results}

The pass rate for the program from 2005 to 2009 is very high with $91 \%$ of the 65 students successfully completing the course. This is a very positive result given that the students take this course in addition to their senior level subjects. Anecdotal evidence also suggests that students were challenged by the additional material and that the extra mathematics proved to be a help, rather than a hindrance, in completing their high school mathematics subjects.

The on-course assessment is identical for both the high school and university students: Figure 1 gives the results for both groups. This figure indicates that the high school students have consistently achieved considerably higher results then the university students. Averaging over the five years indicates 


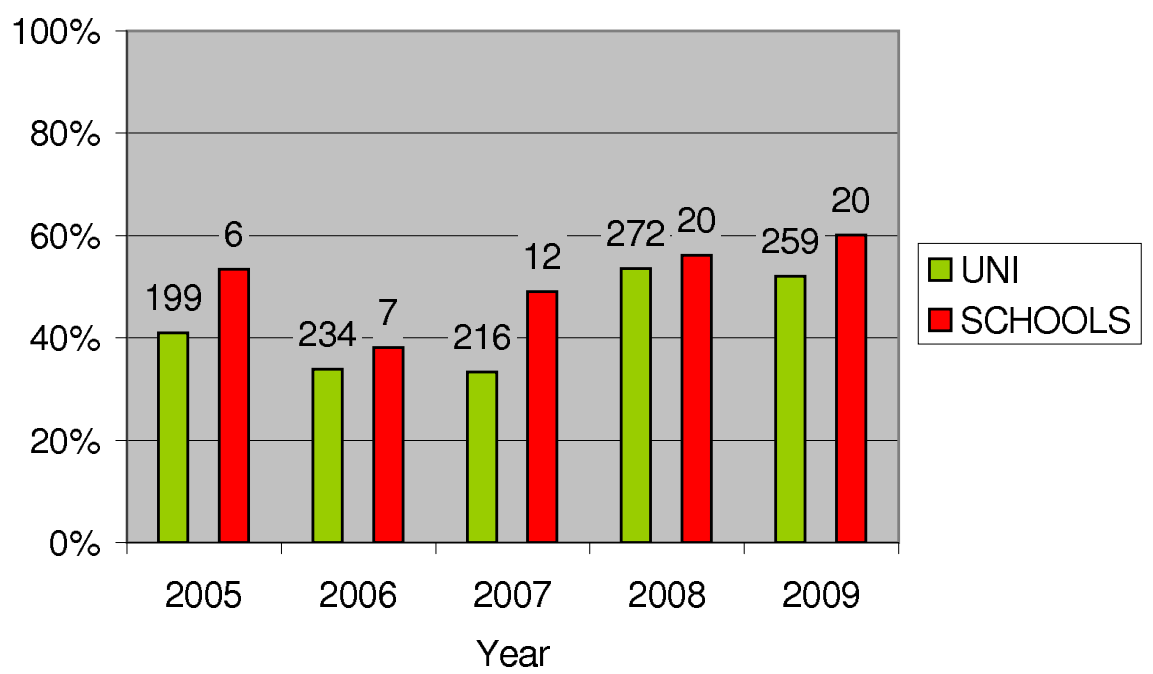

Figure 2: Comparing final exam results for university and high school students for years 2005-2009. The number of students in each class is at the top of the bars.

the high school class results are $11.4 \%$ higher then the university class, which is an encouraging result. However, on-course assessment has not proven to be strong indicator of the student's likelihood of success, as some oncourse material involves online quizzes and written assignments which are not invigilated. Hence the best indicator of a students ability still lies in their performance on the final exam: Figure 2 plots the exam results.

Again we see that the high school students achieved consistently higher than the university class, which indicates that the material delivered in this course is not out of range for the high school students' mathematical abilities. These results are more reassuring than those obtained on the on-course assessment, as the high school students are subject to the same examination conditions as the rest of the class. Although the high school students performed better than the remaining class, this comparison is difficult to make as the school 
students tend to be high achievers who have done one less year of school mathematics.

Regardless of the success or failure of the students in the program, strong links have been formed between the participating high schools, the teachers involved and the mathematics discipline at JCU. It is difficult to measure success in this area, but this program has improved dialogue between the tertiary and secondary teachers involved in the program. Both sides now having a better understanding of what is happening in both the university and high school classrooms. Stronger bonds have also been formed with students in the program who appreciated the opportunity to meet and talk with academics. One of these students in particular, has become very well known to the academic staff and has gone on to tutor mathematics at first year level.

One of the initial aims of the program was to attract the better students to JCU. We have tracked those students who participated in the program and then went on to enrol at JCU. Over the years 2005-2008, 45 students participated in the program, of which 39 went on to study at JCU. Surprisingly, 26 of these students are enrolled into degrees that do not require the mathematics course taught in this program. Initially this appeared to be a poor result; however, further investigation found that a large proportion of these students are enrolled in medical degrees where a firm grounding in mathematics is vital. A further ten students took the opportunity to repeat the course as part of their first year studies, and all of these students improved their grade for the subject. At the moment, credit for the program is only given in the Engineering and Science degrees and we are actively pursuing credit in other degrees, such as education. Hence it is not surprising that only three students chose not to repeat the subject and to use the course as credit towards their degree.

Although the students, teachers and academics involved have not yet been formally surveyed, the anecdotal evidence has been very positive. One of the teachers involved with the program since its inception strongly believes that 
the study of tertiary mathematics was a major contributor to the success of her students in their high school mathematics subjects. Both students and teachers are more than satisfied with the structure of the program, and the results obtained over the last five years. Evidence of this is shown by the fact that the original school involved in the program is once again participating in 2010, as well as the numerous requests received for additional schools to join the program.

\section{Positive outcomes}

\subsection{For the university}

This program has been well received at a faculty and university level, and several other disciplines have adopted a similar program in an attempt to promote their schools outside the university. A major advantage of this program is its potential to attract academically stronger students to JCU. Higher achieving students are more likely to be able to handle the extra workload during their final year of schooling, and it is these students that we are attempting to attract as they are more likely to gain degrees and undertake postgraduate studies.

This program strengthened the link between the university and the participating high schools. It allowed the lecturers at JCU into the classrooms to obtain first hand knowledge of how mathematics is taught in the high schools. This helped us gain knowledge of what first year students expect in lectures. Having a stronger link to the high schools, and in particular the mathematics teachers, also opens up the channels for discussions on common areas of concern. This resulted in a number of useful conversations about falling standards as well valuable discussion on high school mathematics syllabi. 


\subsection{For the school and students}

The program has many advantages for both the schools and students involved. There is no cost incurred by the schools associated with the running of the program, no HECS fees are paid by the students and the subject contributes to the QCE (Queensland Certificate of Education). The additional mathematics learned in the program is also of major benefit in their own high school mathematics subjects. The program is very highly regarded by the schools and most hold special presentations to honour the successful students, as well as using the program for promotional purposes. The students also gain first hand experience of what is expected of them at a tertiary level, as well as forming relationships with the lecturers involved. Visits to the university and the taking of assessment under university conditions should also enhance their first year experience.

\section{$5 \quad$ Potential problems}

The program is taught in the first semester of the university year which coincides with terms one and two of the secondary school year in Queensland. If these students enrol at JCU in the following year, the follow-on subject is taught in the second half of the year, which equates to a 14 month gap between mathematics courses. Although this appeared to be a major problem, most students chose to repeat the course in semester one, effectively eliminating the problem.

While the number of students and schools involved in the program remain small, the university is prepared to waive the HECS fees for these students. However, as the number of schools involved has increased the participation required from JCU staff has also increased, and we struggled to maintain a reasonable level of service. A significant problem will occur when more schools apply pressure to be allowed to participate in the program. As resources are 
limited, the university will be unable to accept all schools that apply, hence causing problems with schools that are not accepted.

The success of this program is largely attributed to the dedication and motivation of the high school teacher involved. Although many schools wish to be involved in the program, it will be difficult to find enough teachers who are prepared to shoulder the extra workload required to teach and administer the course. Although the schools remain very supportive of the program it is left to the individual school to determine whether the teaching of the program is counted as part of their school teaching load.

The final problem is one of logistics. Although it is highly desirable for students to visit the university for a lecture, test or exam it may not be feasible to organise. University lectures are almost always held during the day and would almost certainly conflict with high school lessons. We had reasonable success at organising visits with the relatively small number of schools involved; however, it remains a major problem should more schools enter the program.

\section{Conclusion}

We have detailed a program that was implemented by the mathematics department at JCU, where a standard first year calculus mathematics course is taught to final year high school students. The program ran successfully from 2005-2009 with a total of 65 participating students from five different local high schools. The success or failure of the program can be determined by a number of outcomes. On sheer statistics the students in the program outperformed those in the mainstream university class, with a high percentage of the students successfully completing the course. However, care must be taken when comparing these results, as the number of students involved in the program is small and the majority of these are already high performers and would be expected to succeed. 
However, the greatest success of the program does not lie in the student results, but in the links formed between the university academics, the school teachers and the students. After five years of the program, there is now a much better understanding of what is occurring in both the university and high school classrooms. In collaboration with the school teachers and educationalists we are gradually finding areas of common concern and a combined approach will give us a greater opportunity to effect change. Strong links have also been formed with the students who clearly enjoy the opportunity to interact with the lecturers involved, and anecdotal evidence strongly suggests that participation in the program provided these students with an easier transition from secondary to tertiary studies.

One disappointing aspect of the program is that, although almost all students attend JCU, most do not use the subject as credit towards their degree. Arguments can be made that most students pursued degrees where mathematics is essential, but this does not change the fact that the program has not increased the number of students enrolling in mathematics majors at JCU. Logistical problems also made it difficult for students to physically attend JCU during the program, and this problem would increase should more schools join the program. Even the increase in the number of participating schools from 2005 until the present stretched the JCU academics, who find it increasingly difficult to regularly visit the schools.

Overall, the program has been deemed to be successful by both the university and schools involved. However, although the short term future of the program is assured, the shortage of highly motivated school teachers and the limited number of JCU mathematicians will ensure that the number of schools and students involved in the program will remain relatively small. 


\section{References}

[1] S. Barry and I. Chapman, Predicting University Performance.

ANZIAM J., 49(E):C36-C50, 2007. http://anziamj . austms.org.au/ ojs/index.php/ANZIAMJ/article/view/304/145. C642

[2] C. Bellimo and R. Strapp, A survey of advanced mathematics topics: a new high school mathematics class International Journal of Mathematical Education in Science and technology, 39 no. 1, 2008, 13-22. C643

[3] S. Belward, D. Mullamphy, W. Read and G. Sneddon, Preparation of Students for Tertiary studies involving Mathematics. ANZIAM J., 48(E):C840-C857, 2007.

http://anziamj . austms . org. au/V47EMAC2005/Belward/home.html. C641

[4] D. Bressoud, Meeting the Challenge of High School Calculus. MAA Focus, 30(1):27, 2010.

http://www.maa.org/pubs/febmar10_focus.pdf C643

[5] A. Heck and L. Van Gastel, Mathematics on the Threshold International Journal of Mathematical Education in Science and technology, 37 no. 8, 2006, 925-945. doi:10.1080/00207390600819003. C642

[6] M. Hourigan and J. O'Donoghue, Mathematical Underpreparedness; the influence of the pre-tertiary mathematics experience on students' ability to make a successful transition to tertiary level mathematics courses in Ireland International Journal of Mathematical Education in Science and technology, 38 no. 4, 2007, 461-476. doi:10.1080/00207390601129279. C642

[7] A. Kajander and M. Lovric, Transition from secondary to Tertiary Mathematics International Journal of Mathematical Education in 
Science and technology, 36 nos. 2-3, 2005, 149-160. C642

[8] H. Luk, The gap between Secondary School and University Mathematics International Journal of Mathematical Education in Science and technology, 36 nos. 2-3, 2005, 161-174. doi:10.1080/00207390412331316988. C642

[9] L. Mackenzie, Engaging Secondary Students in the University Experience, Ninth Pacific Rim Conference First Year in Higher Education: Nuts and Bolts Presentation, 2006 http://www.fyhe.com. au/past_papers/2006/Nuts\%20\%26\%20Bolts/MacKenzie.pdf. C643

[10] Bulletin for AP Students and Parents, The College Board, 2009. http://professionals.collegeboard.com/profdownload/ ap-student-parent-bulletin-2009-10.pdf. C643

\section{Author addresses}

1. P. J. Higgins, School of Engineering and Physical Sciences, James Cook University, Townsville, Australia. mailto:patrick.higgins@jcu.edu.au

2. D. F. Mullamphy, School of Engineering and Physical Sciences, James Cook University, Townsville, Australia.

3. S. R. Belward, School of Engineering and Physical Sciences, James Cook University, Townsville, Australia. 